\title{
Effect of Private and Common Areas on Transaction Price for Collective Housing
}

\author{
Ho-wen Yang \\ Associate Professor, \\ Department of Land Management \\ University of Feng Chia \\ Hsien-chi Hsieh* \\ $\mathrm{Ph} . \mathrm{D}$. Program for Civil Engineering, \\ Water Resources Engineering, and Infrastructure \\ PlanningUniversityof Feng Chia \\ No100, Wen hua Rd., Taichung City, Taiwan (ROC)
}

\begin{abstract}
The utility of a private area in a residential building (collective housing) is higher than that of a common or shared area; thus, the price of private areas should be higher than that of common areas. However, in sales transactions, both areas are included in the price borne by the purchaser. The scope of this study was 22 residential buildings near Zhongke Shopping Plaza, Xitun District, Taichung City, and data for 2,500 transactions were analyzed. The study employed hierarchical linear models, with residential unit price as the dependent variable and private and common areas as independent variables, to explore the extent to which these types of area affect the transaction price, and the effect of each area type on the housing price was clarified. In different models, the results indicate that common and private areas have varying degrees of influence on the housing price; however, the influence of common areas is greater than that of private areas. This finding subverts traditional concepts and previous results.
\end{abstract}

Keywords-collective housing, private area, common area, hierarchical linear model

\section{Introduction}

Pricing in multiunit residential structures (e.g., apartment buildings) in the United States and Japan is calculated based on the private area (i.e., the part of the building referred to as a unit or apartment) and not the common or shared area. In Taiwan, housing prices are calculated based on both private and common areas. The pricing of shared areas is the same as that of private areas, but most consumers believe that shared facilities contribute less to housing prices than do private areas (Wang, Zhang, \& Jiang,2018). Chan et al. (2008) explored the effect of private and common areas of residential buildings (collective housing) on housing prices and determined that consumers are willing to pay a higher price for an exclusive (i.e., private) area.

The main purpose of this study was to understand the extent to which private and common areas of a residential building contribute to the total price of a housing unit and to clarify whether the effect of a private area on pricing is greater than that of a common or shared area. The results will provide consumers with a deeper understanding of distribution of the value of various parts of real estate.

The first section introduces the study motivation and purpose. The second section provides a review of the domestic and foreign literature. The third section describes the methodology of the study; hierarchical linear models (HLMs) were employed. The fourth section presents the study design, including the research framework, setting of variables, and application of HLMs. The fifth section presents the findings obtained through the exploration of the results of each model. The paper concludes with a discussion of the effects of private and shared areas on housing prices.

\section{Literature Review}

Shared facilities and management costs influence housing prices. Tseand Love(2000) determined that the shared facilities of a residential building improve the convenience and comfort of residents. Benefield (2009) found that some shared facilities influence housing prices. Mok et al. (1995), Tse (2000), and Jim and Chen (2009) have determined that some club facilities also influence the prices. Wang et al. (2018) explored the effect of shared facilities on the housing price and found that the common area of residential buildings has a large influence on real estate prices. Chen, Lin, and 
Chen(2010) proposed that the purpose of maintenance and management of residential buildings is to delay the depreciation of common areas by increasing the service life of shared facilities or maintaining their quality.

The management and maintenance situation and the quality of shared facilities have a large effect on real estate prices, and the type of shared facility also has an effect. General shared facilities have a large influence on prices. Wen and Lin (2009) mentioned that excessive shared facilities may cause high management fees, which in turn affect consumer willingness to purchase the real estate.

Wang et al. (2018) found that private areas have a larger contribution to housing prices than that shared facilities. Chan et al. (2008) explored the effects of private and common areas of residential buildings on housing prices and determined that consumers are willing to pay a higher price for a proportionally larger private area. So and Leung (2004) found that compared with individuals in Taiwan and Singapore, people in Hong Kong are less willing to pay for common areas and equipment in residential buildings.

The characteristic price model is the most commonly used method for determining housing prices. Tong (2008) proposed this method, which uses the ordinary least squares estimator. However, in this method, all data are considered as a single class, and the characteristics of residential goods are neglected, such as spatial dependencies and heterogeneity. Huang (2012) argued that housing data have hierarchical attributes, wherein the characteristic factors of different levels in an HLM have diverse effects on residential prices. Furthermore, the characteristic factors have mutual effects, and the effect of each factor on housing prices should be adjusted for.

According to the literature, management costs and shared facilities influence residential prices. Most researchers have included only certain characteristics of shared facilities and have used the characteristics of private units to establish characteristic price models. HLMs are rarely used to explore the effect of different combinations of management costs, shared facilities, and private areas on housing prices. For example, Wang et al. (2018) indicated that the price ratio of residential common to private areas is $32 \%$; they argued that the price of a unit can be reliably calculated using this ratio. However, they did not consider that shared facilities differ. For each transaction case, the proportion of the common area price to the private area price may vary. The applicability of their model to all residential buildings should be investigated.

\section{Methodology}

In HLMs, also known as multilevel models, a single-level analysis concept is used to process nests and analyze data. Wen and Qiu (2012) stated that in data analysis, the traditional general linear model framework can only describe the relationships between variables at a single level and has only one error term, which belongs to the individual level. HLMs can be used for different levels of data that include individuals and populations. Zhang and Lin (2018) stated that in an HLM, the intercept and slope terms at an individual level regression are considered as a variable dependent on the group-level, and the effect of the group-level error term can be determined. A random effect is used to estimate the intercept and slope terms at the individual level to check whether the variance of its residuals is significant. If it is significant, this means that the hierarchy of the group-level variables affects the terms.

From this description, it is clear that an HLM differs from a traditional general linear model. It can process different levels of data and calculate the interaction adjustment effect between variables to reduce error. Because the purpose of this study was to explore the effect of management costs, common areas, and private areas on housing prices at different levels, HLMs were adopted.

\section{Research Design}

The area under study is located near Zhongke Shopping Plaza in Xitun District, Taichung City. The location is bordered by Dongda Road Section 1, Zhongke Road, Xitun Road Section 3, and Huanzhong Road Section 2. The area contains residential buildings at least 12 stories high. The transaction cases were relatively concentrated, and construction was phased; thus, it was easy to observe how changes in laws and regulations affected the proportion of shared facilities and their influence on the price.

The remainder of this section presents the research framework to describe the variables, data collection methods, and data analysis.

\subsection{Selection of variables}

Building and unit characteristics were divided into group- and individual-level variables. Figure 1 illustrates the framework and shows how both sets of variables affect residential prices. The selected dependent variable, group-level hierarchical variables, and individual-level hierarchical variables are as follows.

\subsubsection{Dependent variable}


The study explored the relationship between shared facilities and the price of residential units. The total price of selected residential units was a dependent variable (the total price was calculated by subtracting the transaction price of the unit from the parking space price; the price is expressed in million NTD).

\subsubsection{Group-level variable}

Chen and Lin (2013) proposed that the effective management and maintenance of shared facilities after construction influence housing values. Therefore, in this study, management costs were predicted to influence the price.

\subsubsection{Individual-level variables}

\subsubsection{Story}

Real estate products are heterogeneous: units are on different stories and ventilation and lighting differ, as does the surrounding landscape. In addition, the lower floors are more susceptible to external noise and have sunlight exposure. Therefore, prices are usually related to story. In this study, story was expected to be positively associated with the price.

\subsubsection{Age}

Liang (2015) found that the value of real estate shows a reverse depreciation phenomenon, wherein the value initially drops and then rises during the life of a building. However, Cai (2009) argued that the housing price depreciates over time. Therefore, in this study, the age of the residential unit at the time of the transaction was expected to be negatively associated with the price.

\subsubsection{Common area}

Parking spaces are not included in common areas. These areas include shared facilities such as gyms, audiovisual rooms, and swimming pools. Their overall purpose is to improve the comfort of residents; the larger the common housing area, the more shared facilities that can be enjoyed by residents. Therefore, in this study, the common area was expected to have a positive association with the price.

\subsubsection{Private area}

When real estate is sold, the private area (i.e., housing unit) is the most important component. It is the main living space of the household. In this study, the private area was expected to have a positive association with the price.

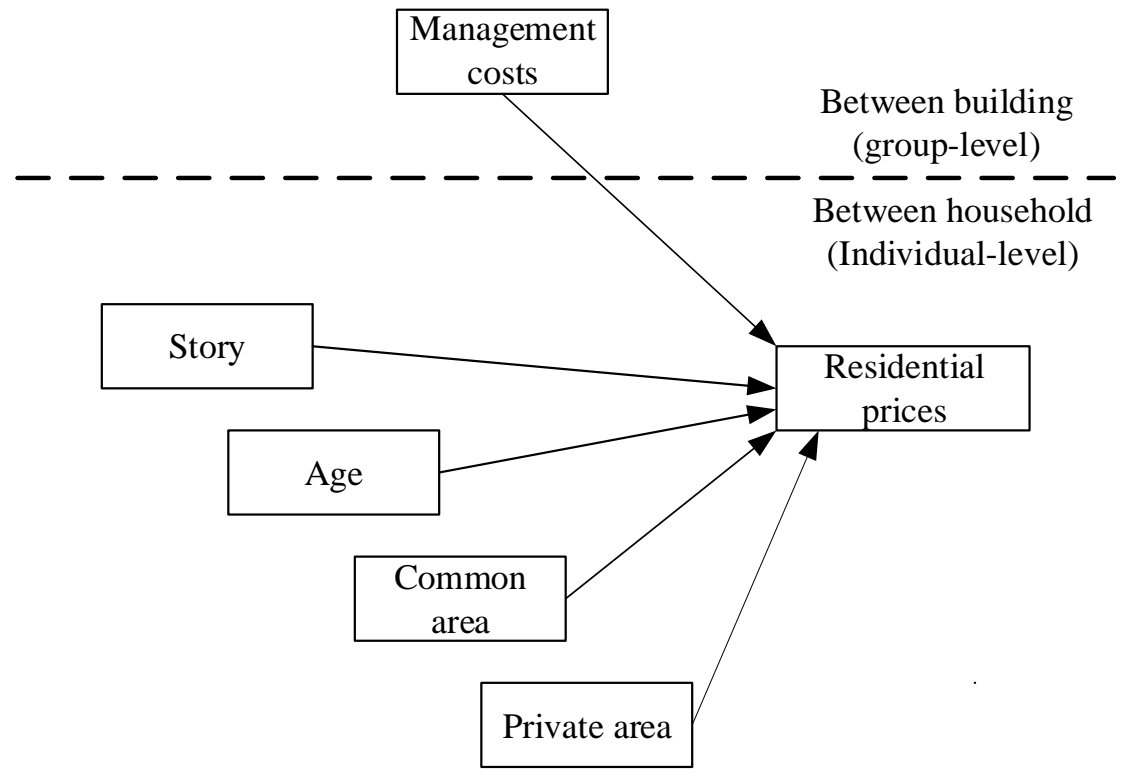

Fig. 1 Research framework diagram

\subsection{Data collection methods}

The scope of this research was initially 28 residential buildings near Zhongke Shopping Plaza, Xitun District, Taichung City. Using information obtained from the real-value registration of real estate transactions published by the Ministry 
of the Interior and information provided by the construction management company, a total of 3,282 transactions from April 2012 to March 2019 were obtained.

A database was created. Cases with remarks and those with errors in the registered content were removed. The remaining 2,500 valid transactions were distributed in 22 buildings.

\subsection{Data analysis method: HLMs}

The price in residential transactions is affected not only by the individual characteristics of the building but also by other(group-level) factors. In this study, the individual characteristics of the building were measured at Level 1, and the group-level factors of the residential building in which they are located were measured at Level 2 (Tables 1 and 2).

\subsubsection{Model 0: Null model}

A one-way ANOVA model with random effects (also known as a non-model, nihilistic model, or Null model) does not include any individual- or group-level explanatory variables.

Zero model analysis has the following purposes: to test for differences between groups; estimate how much of the total variation is caused by variation between groups; and provide preliminary information for comparison purposes when using a hierarchical linear or general regression analysis model.

Level 1: $\mathrm{Y}_{\mathrm{ij}}=\beta_{0 \mathrm{j}}+\varepsilon_{i j}(i=1,2,3 \ldots, \mathrm{n} i ; j=1,2,3 \ldots, 22)$ (Equation 3-1)

Level 2: $\beta_{0 \mathrm{j}}=\gamma_{00}+\mu_{0 \mathrm{j}} \quad$ (Equation 3-2)

Mixed formula: $\mathrm{Y}_{\mathrm{ij}}=\gamma_{00}+\mu_{0 \mathrm{j}}+\varepsilon_{i j}$ (Equation 3-3)

4.3.2 Model 1: One-way analysis of covariance model with random effects

In the One-way analysis of covariance model with random effects, four variables were assigned to the individual level: story, age, common area, and private area.

At Level 2, the error terms of the equations with the four slope terms as the result variables were all set to fixed effects, assuming no difference in the effect of the variables on residential prices among residential buildings.

With this model, after introducing individual-level variables to control or exclude the effect of covariables on residential prices, it is possible to determine whether prices for each residential building remain significantly different. Level $1: \mathrm{Y}_{\mathrm{ij}}=\beta_{0 \mathrm{j}}+\beta_{1 \mathrm{j}} \times\left(\right.$ Story $\left._{\mathrm{ij}}\right)+\beta_{2 \mathrm{j}} \times\left(\right.$ Age $\left._{\mathrm{ij}}\right)+\beta_{3 \mathrm{j}} \times\left(\right.$ Common area $\left.\mathrm{ij}_{\mathrm{j}}\right)+\beta_{4 \mathrm{j}} \times\left(\right.$ Private area $\left.\mathrm{a}_{\mathrm{ij}}\right)+\varepsilon_{i j}(i=1,2,3 \ldots, \mathrm{n} i ; j=1,2,3 \ldots$, 22)(Equation 3-4)

Level 2: $\beta_{0 \mathrm{j}}=\gamma_{00}+\mu_{0 \mathrm{j}}($ Equation 3-5)

$\beta_{1 \mathrm{j}}=\gamma_{10}$ (Equation 3-6)

$\beta_{2 \mathrm{j}}=\gamma_{20}$ (Equation 3-7)

$\beta_{3 \mathrm{j}}=\gamma_{30}$ (Equation 3-8)

$\beta_{4 \mathrm{j}}=\gamma_{40}$ (Equation 3-9)

Mixed formula: $\mathrm{Y}_{\mathrm{ij}}=\gamma_{00}+\gamma_{10} \times\left(\right.$ Story $\left._{\mathrm{ij}}\right)+\gamma_{20}\left(\mathrm{Age}_{\mathrm{ij}}\right)+\gamma_{30} \times\left(\right.$ Common area $\left._{\mathrm{ij}}\right)+\gamma_{40}\left(\right.$ Private area $\left._{\mathrm{ij}}\right)+\mu_{0 \mathrm{j}}+\varepsilon_{i j}$ (Equation3-10)

4.3.3 Model 2: Random coefficients regression model

In the random coefficients regression model, four variables were assigned to the individual level: story, age, common area, and private area. At Level 2, the error terms of the equations with the four slope terms as the result variables were all set to random effects. It was assumed that the influence of the residential building on the unit price was random. Random denoted the slope coefficient of the effects of story, age, common area, and private area on prices in each building. Differences may exist between residential buildings.

This model can test whether the individual (story, age, common area, private area)-level variables had a significant effect on prices between buildings.

Level $1: \mathrm{Y}_{\mathrm{ij}}=\beta_{0 \mathrm{j}}+\beta_{1 \mathrm{j}} \times\left(\right.$ Story $\left._{\mathrm{ij}}\right)+\beta_{2 \mathrm{j}} \times\left(\right.$ Age $\left._{\mathrm{ij}}\right)+\beta_{3 \mathrm{j}} \times\left(\right.$ Common area $\left.\mathrm{a}_{\mathrm{ij}}\right)+\beta_{4 \mathrm{j}} \times\left(\right.$ Private area $\left._{\mathrm{ij}}\right)+\varepsilon_{i j}(i=1,2,3 \ldots, \mathrm{n} i ; j=1,2,3 \ldots$, 22) (Equation3-11)

Level 2: $\beta_{0 \mathrm{i}}=\gamma_{00}+\mu_{0 \mathrm{j}}$ (Equation 3-12)

$\beta_{1 \mathrm{i}}=\gamma_{10}+\mu_{1 \mathrm{i}}$ (Equation 3-13)

$\beta_{2 \mathrm{i}}=\gamma_{20}+\mu_{2 \mathrm{i}}$ (Equation 3-14)

$\beta_{3 \mathrm{i}}=\gamma_{30}+\mu_{3 \mathrm{i}}$ (Equation 3-15)

$\beta_{4 \mathrm{j}}=\gamma_{40}+\mu_{4 \mathrm{j}}($ Equation 3-16) 
Mixed formula: $Y_{\mathrm{ij}}=\gamma_{00}+\gamma_{10} \times\left(\right.$ Story $\left._{\mathrm{ij}}\right)+\gamma_{20} \times\left(\right.$ Age $\left._{\mathrm{ij}}\right)+\gamma_{30} \times\left(\right.$ Common area $\left.\mathrm{ij}_{\mathrm{ij}}\right)+\gamma_{40} \times\left(\right.$ Private area $\left._{\mathrm{ij}}\right)+\mu_{0 \mathrm{j}}+\mu_{1 \mathrm{j}} \times\left(\right.$ Story $\left._{\mathrm{ij}}\right)+$

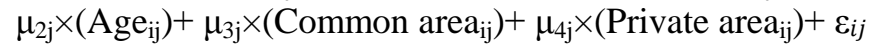

(Equation3-17)

4.3.4 Model 3: Means as outcomes regression model

In the means as outcomes regression model as the result, no individual-level variable was assigned to Level 1; the basic transaction price for each residential building at Level 1 was used as the dependent variable at Level 2. The variable at the group-level of input was management costs.

The purpose of this model was to detect whether the management cost at Level 2 had a direct effect on the average transaction price of units between different residential buildings.

$$
\text { Level } 1: \mathrm{Y}_{\mathrm{ij}}=\beta_{0 \mathrm{j}}+\varepsilon_{i j} \quad(i=1,2,3 \ldots, \mathrm{n} i ; j=1,2,3 \ldots, 22) \quad \text { (Equation 3-18) }
$$

Level 2: $\beta_{0 \mathrm{j}}=\gamma_{00}+\gamma_{01} \times($ management costs $\mathrm{j})+\mu_{0 \mathrm{j}}($ Equation 3-19)

Mixed formula: $\mathrm{Y}_{\mathrm{ij}}=\gamma_{00}+\gamma_{01} \times($ management costs $\mathrm{j})+\mu_{0 \mathrm{j}}+\varepsilon_{i j}($ Equation 3-20)

\subsubsection{Model 4: contextual effect model}

In the contextual effect model, four variables were invested at the individual level: story, age, common area, and private area. The group-level of the equation with the intercept as the result variable was assigned to the group-level variable-management costs.

In this model, because the individual- and group-level variables were simultaneously assigned, the estimated value means that after controlling for the group-level variables in the model, the significance of the effect of the individuallevel variables and the group-level variable (after controlling for individual-level variables) on the price can be determined.

Level 1: $\mathrm{Y}_{\mathrm{ij}}=\beta_{0 \mathrm{j}}+\beta_{1 \mathrm{j}} \times\left(\right.$ Story $\left._{\mathrm{ij}}\right)+\beta_{2 \mathrm{j}} \times\left(\right.$ Age $\left._{\mathrm{ij}}\right)+\beta_{3 \mathrm{j}} \times\left(\right.$ Common $\left.\operatorname{area}_{\mathrm{ij}}\right)+\beta_{4 \mathrm{j}} \times\left(\right.$ Private area $\left._{\mathrm{ij}}\right)+\varepsilon_{i j}(i=1,2,3 \ldots, \mathrm{n} i ; j=1,2,3 \ldots$, 22) (Equation 3-21)

Level 2: $\beta_{0 \mathrm{i}}=\gamma_{00}+\gamma_{01} \times($ management costs $\mathrm{j})+\mu_{0 \mathrm{j}} \quad$ (Equation 3-22)

$$
\beta_{1 \mathrm{i}}=\gamma_{10}+\mu_{1 \mathrm{i}} \quad \text { (Equation 3-23) }
$$

$\beta_{2 \mathrm{i}}=\gamma_{20}+\mu_{2 \mathrm{i}}$ (Equation 3-24)

$\beta_{3 \mathrm{i}}=\gamma_{30}+\mu_{3 \mathrm{i}}$ (Equation 3-25)

$\beta_{4 \mathrm{j}}=\gamma_{40}+\mu_{4 \mathrm{j}}$

(Equation 3-26)

Mixed formula: $Y_{\mathrm{ij}}=\gamma_{00}+\gamma_{01} \times($ management costs $\mathrm{j})+\gamma_{10} \times\left(\right.$ Story $\left._{\mathrm{ij}}\right)+\gamma_{20} \times\left(\right.$ Age $\left._{\mathrm{ij}}\right)+\gamma_{30} \times\left(\right.$ Common area $\left._{\mathrm{ij}}\right)+\gamma_{40} \times($ Private $\left.\operatorname{area}_{\mathrm{ij}}\right)+\mu_{0 \mathrm{i}}+\mu_{1 \mathrm{i}} \times\left(\right.$ Story $\left._{\mathrm{ij}}\right)+\mu_{2 \mathrm{i}} \times\left(\right.$ Age $\left._{\mathrm{ij}}\right)+\mu_{3 \mathrm{i}} \times\left(\right.$ Common area $\left._{\mathrm{ij}}\right)+\mu_{4 \mathrm{i}} \times\left(\right.$ Private area $\left._{\mathrm{ij}}\right)+\varepsilon_{i j}$

\begin{tabular}{|c|c|}
\hline Variable & Description \\
\hline $\mathrm{Y}_{\mathrm{ij}}$ & $\begin{array}{l}\text { Residential transaction price for the } \mathrm{i} \text {-th residential unit in the } \mathrm{j} \text {-th } \\
\text { residential building(price of parking space deducted) }\end{array}$ \\
\hline$\beta_{0 j}$ & Unit base transaction price for $\mathrm{j}$-th residential building \\
\hline Story $_{\mathrm{ij}}$ & Story of the i-th residential unit in the j-th residential building \\
\hline$\beta_{1 \mathrm{j}}$ & $\begin{array}{l}\text { The effect of the story of the } \mathrm{j} \text {-th residential building on the transaction } \\
\text { price of the unit }\end{array}$ \\
\hline $\mathrm{Age}_{\mathrm{ij}}$ & Age of the i-th residential unit in the j-th residential building \\
\hline$\beta_{2 \mathrm{j}}$ & $\begin{array}{l}\text { The effect of the age of the } \mathrm{j} \text {-th residential building on the transaction } \\
\text { price of the unit }\end{array}$ \\
\hline Common area $\mathrm{ij}_{\mathrm{ij}}$ & Common area of the $\mathrm{i}$-th residential unit in the $\mathrm{j}$-th residential building \\
\hline$\beta_{3 j}$ & $\begin{array}{l}\text { The effect of the common area of the } \mathrm{j} \text {-th residential building on the } \\
\text { transaction price of the unit }\end{array}$ \\
\hline Private area $_{\mathrm{ij}}$ & Private area of $\mathrm{i}$-th residential unit in $\mathrm{j}$-th residential building \\
\hline$\beta_{4 j}$ & $\begin{array}{l}\text { The effect of the private area of the jth residential building on the } \\
\text { transaction price of the unit }\end{array}$ \\
\hline$\varepsilon_{i j}$ & Price error term for the i-th residential unit of the $\mathrm{j}$-th residential building \\
\hline
\end{tabular}

(Equation 3-27)

Table 1. Hierarchical Linear Model Level 1 
Table 2. Hierarchical Linear Model Level 2

\begin{tabular}{|c|c|}
\hline Variables & Description \\
\hline$\gamma 00$ & Average residential transaction price for all residential buildings \\
\hline$\gamma 01$ & $\begin{array}{l}\text { The effect of the "management costs" context variable on the price of } \\
\text { residential transactions }\end{array}$ \\
\hline $\begin{array}{l}\text { manageme } \\
\text { nt costs } j\end{array}$ & Management costs for $\mathrm{j}$-th residential building \\
\hline$\mu_{0 j}$ & Error terms affecting $\beta_{0 \mathrm{j}}$ \\
\hline$\gamma 10$ & $\begin{array}{l}\text { The effect of the story of individual levels of residential units in each } \\
\text { building on the transaction price }\end{array}$ \\
\hline$\mu_{1 j}$ & Error terms affecting $\beta_{1 j}$ \\
\hline$\gamma 20$ & $\begin{array}{l}\text { The effect of the age of individual levels of residential units in each } \\
\text { building on the transaction price }\end{array}$ \\
\hline$\mu_{2 j}$ & Error terms affecting $\beta_{2 j}$ \\
\hline$\gamma 30$ & $\begin{array}{l}\text { The effect of the common area of individual levels of residential units in } \\
\text { each building on the transaction price }\end{array}$ \\
\hline$\mu_{3 j}$ & Error terms affecting $\beta_{3 j}$ \\
\hline$\gamma 40$ & $\begin{array}{l}\text { The effect of the private area of individual levels of residential units in each } \\
\text { building on the transaction price }\end{array}$ \\
\hline$\mu_{4 j}$ & Error terms affecting $\beta_{4 j}$ \\
\hline
\end{tabular}

\section{Findings}

The HLM results (Table 3) are discussed in this section.

\subsection{Model 0 (Null model)}

$\gamma_{00}=9.437689(\mathrm{p}<0.01)$, which means that the average transaction price of residential units in this area was 9.437689 million NTD. Variation in the average difference in the price between buildings was as follows: $\tau_{00}=18.932582$. Variation of the price between units within a building was as follows: $\sigma^{2}=3.542858$. ICC $=18.932582 /(3.542858+$ $18.932582)=0.842$.Among the variables representing the transaction price of units, $84.2 \%$ can be explained by the building variables. In addition, the estimated value of $\gamma_{00}$ reached a statistically significant level, indicating a significant difference in the average transaction price between buildings.

5.2 Model 1 (One-way analysis of covariance model with random effects)

$\gamma_{10}=0.057321(\mathrm{p}<0.01), \gamma_{30}=0.387895(\mathrm{p}<0.01)$, and $\gamma_{40}=0.133461(\mathrm{p}<0.01)$ all reached statistically significant levels, indicating that in each building, story, common area, and private area of units had a significant and positive effect on the transaction price. Adding one unit to a story in any building would increase the transaction price by 0.057321 million NTD. Adding one unit to the common area of any building would increase the price by 0.387895 million NTD. Adding one unit to the private area in any building would increase the price by 0.133461 million NTD.

$\tau_{00}=2.755910(\mathrm{p}<0.01)$, which is statistically significant. After controlling for the effect of story, age, common area, and private area of individual-level residential units on the price (assuming that the effect of variables on the price is the same across buildings), a significant difference in the average price was found. Compared with the zero model results, $\tau_{00}$ decreased from 18.932582 to 2.759910 . The percentage reduction of variation was $(18.932582-2.755910) / 18.932582=85.4 \%$.From the perspective of the variation in the difference in the price between units within a building, $\sigma^{2}$ decreased from 3.542858 to 1.069790 . The percentage reduction of the variation was $(3.542858-1.069790) /(3.542858)=69.8 \%$.The individual level of Level 1 incorporated four explanatory variables, which could explain the reduction in variation. In addition, the Akaike information criterion (AIC) value decreased from 10383.243 to 7401.510 , denoting a decrease of 2981.733 . The single-factor analysis of covariance model with random effects had a better fit than the zero model.

\subsection{Model 2 (random coefficients regression model)}

$\gamma_{10}=0.053725(\mathrm{p}<0.01), \gamma_{30}=0.267303(\mathrm{p}<0.05)$, and $\gamma_{40}=0.166524(\mathrm{p}<0.01)$ all reached statistically significant levels, indicating that in each building, story, common area, and private area had a significant and positive effect on the transaction price. Adding one unit to the story in any residential building increased the transaction price by 0.053725 million NTD. Adding one unit to the common area increased the price by 0.267303 million NTD. Adding one unit to the private area increased the price by 0.166524 million NTD. 
$\tau_{00}=3.350547(\mathrm{p}<0.05)$, which is statistically significant. After controlling for the effect of story, age, common area, and private area of individual-level residential units on the price (assuming that the effect of each variable on the price varies between buildings), a significant difference in the average price remained. Compared with the zero model results, $\tau_{00}$ decreased from 18.932582 to3.350547.

The percentage reduction of variation was $(18.932582-3.350547) / 18.932582=82.3 \%$. Regarding the variation in the difference in the price between units within a building, $\sigma^{2}$ decreased from 3.542858 to 0.558078 . The percentage reduction of variation was $(3.542858-0.558078) / 3.542858=84.2 \%$. The individual level at Level 1 incorporated four explanatory variables, which could explain the reduction in variation. In addition, the AIC value decreased from 10383.243 to5988.331, denoting a decrease of 4394.912. The model fit of the regression model with random coefficients was better than that of the single-factor analysis of covariance model with random effects.

$\tau_{11}=0.003178(\mathrm{p}<0.05)$ and $\tau_{22}=0.165769(\mathrm{p}<0.01)$ all reached statistically significant levels, indicating that the effects of story and age were statistically significant. Their degree of influence on the price between buildings was significantly different.

5.4 Model 3 (means as outcomes regression model)

$\gamma_{01}=.092547(\mathrm{p}<0.1)$ reached a statistically significant level, indicating that management costs had a significant effect on the average price between buildings.

$\tau_{00}=16.798587(\mathrm{p}<0.01)$ reached a statistically significant level, which means that when controlling for management costs, a significant difference existed in the average price between buildings.

5.5 Model 4: contextual effect model

$\gamma_{01}=0.040549(\mathrm{p}<0.1)$ reached a statistically significant level, indicating that when controlling for the effects of individual-level explanatory variables on the price, management costs (the context variable) had a positive effect on the average price. For each additional unit of management cost, the average price increased by 0.040549 million NTD.

$\gamma_{10}=0.053932(\mathrm{p}<0.01), \gamma_{30}=0.245634(\mathrm{p}<0.05)$, and $\gamma_{40}=0.175402(\mathrm{p}<0.01)$ all reached statistically significant levels, indicating that when controlling for the effect of management costs on the price and the number of units in each residential building, story, shared area, and private area had significant effects on the price.

The story, common area, and private area of a unit had a positive effect on residential transaction prices. Adding one unit to story increased the price by 0.053932 million NTD. Adding one unit to the common area increased the price by 0.245634 million NTD. Adding one unit to the private area increased the price by 0.175402 million NTD.

$\tau_{00}=2.774452(\mathrm{p}<0.05)$ reached a statistically significant level, indicating that when controlling for the effects of story, age, common area, private area, and management costs (context variable)on prices, a significant difference in the average price between buildings remained. Compared with the zero model results, $\tau_{00}$ decreased from 18.932582 to2.774452. The percentage reduction of variation was $(18.932582-2.774452) / 18.932582=85.3 \%$. With regard to the variation in the difference in prices between units within a building, $\sigma^{2}$ decreased from 3.542858 to 0.558201 . The percentage reduction of variation was $(3.542858-0.558201) / 3.542858=84.2 \%$.

$\tau_{11}=0.003157(\mathrm{p}<0.05)$ and $\tau_{22}=0.165206(\mathrm{p}<0.01)$ reached statistically significant, indicating that story and ageexerted significant effects. A significant difference was found in the degree of their influence on the average price of residential units between buildings. 
Table 3. Comparison of HLMs

\begin{tabular}{|c|c|c|c|c|c|}
\hline Parameter estimates & Model0 & Model1 & Model2 & Model3 & Model4 \\
\hline \multicolumn{6}{|l|}{ Fixed effect } \\
\hline $\begin{array}{l}\quad \gamma_{00} \\
\quad \text { (average residential } \\
\text { transaction price for all } \\
\text { residential buildings) }\end{array}$ & 9.437689 & 8.414423 & 8.983740 & 4.181037 & 6.598298 \\
\hline \multicolumn{6}{|l|}{$\begin{array}{l}\text { Context variable } \\
\text { /explaining variable }\end{array}$} \\
\hline $\begin{array}{c}\gamma_{01} \quad \text { (management } \\
\text { costs) }\end{array}$ & & & & 0.092547 & 0.040549 \\
\hline \multicolumn{6}{|l|}{ slope } \\
\hline$\gamma_{10}$ (story) & & 0.057321 & 0.053725 & & 0.053932 \\
\hline$\gamma_{20}($ age $)$ & & $1^{-0.00105}$ & $6^{-0.00871}$ & & -0.000528 \\
\hline$\gamma_{30}($ common area $)$ & & 0.387895 & 0.267303 & & 0.245634 \\
\hline$\gamma_{40}($ private area) & & 0.133461 & 0.166524 & & 0.175402 \\
\hline \multicolumn{6}{|l|}{ Random effect } \\
\hline$\mu_{0 \mathrm{j}}$ variation $\tau_{00}$ & 18.932582 & 2.755910 & 3.350547 & $\begin{array}{ll} & 16.79858 \\
7 & \end{array}$ & 2.774452 \\
\hline$\mu_{1 \mathrm{j}}$ variation $\tau_{11}$ & & & 0.003178 & & 0.003157 \\
\hline$\mu_{2 \mathrm{j}}$ Variation $\tau_{22}$ & & & 0.165769 & & 0.165206 \\
\hline$\mu_{3}$ variation $_{\mathrm{j}} \tau_{33}$ & & & 0.038949 & & 0.038547 \\
\hline$\mu_{4 \mathrm{j}}$ variation $\tau_{44}$ & & & 0.002143 & & 0.002484 \\
\hline$\varepsilon_{\mathrm{ij}}$ variation $\sigma^{2}$ & 3.542858 & 1.069790 & 0.558078 & 3.542879 & 0.558201 \\
\hline AIC & 10383.243 & 7401.510 & 5988.331 & $8^{10383.98}$ & 5991.048 \\
\hline
\end{tabular}

\section{Conclusion}

This study explored the effects of the private area and common or shared area on the transaction price for residential buildings near Zhongke Shopping Plaza in Xitun District, Taichung City. The analysis, which was conducted using HLMs, provided the following conclusions.

a. In the Null model (Model 0), a significant difference exists in the average price between buildings without any explanatory variables.

b. The one-way analysis of covariance model with random effects (Model 1) introduced individual-level explanatory variables for Level 1 to explore the effect of self-variable terms at the individual level on the dependent variable. The results indicate that for each increase in the story, common area, and private area, the transaction price increases by NTD57,321, NTD387,895, and NTD133,461, respectively.

c. In the random coefficients regression model (Model 2), story, common area, and private area have a positive and significant effect on the price. The results indicate that for each increase in story, common area, and private area, the price increases by NTD53,725, NTD267,303, and NTD166,524, respectively.

d. In the means as outcomes regression model as the result (Model 3), management costs have a significant effect on the average price between residential buildings. When management costs are controlled, a significant difference exists in the average price between buildings.

e. The contextual effect model (Model 4) indicates that after controlling for individual-level explanatory variables on the price, management costs have a positive effect on the average price. For each additional unit of management cost, the average price increases by NTD40,549. However, after controlling for management costs on the price, story, common area, and private area have a significant effect on the price. For each additional unit for story, shared area, and private area, the transaction price of a residential unit increases by NTD53,932, NTD245,634, and NTD175,402, respectively. 
According to the results, in Model 0, without considering any variables, the average transaction price of residential units in this research area was NTD9,437,689. When the fixed effect is considered (Model 1), individual-level variables are included. For each additional unit of story, common area, and private area, the price increases by NTD57,321, NTD387,895, and NTD133,461, respectively, with a positive effect on the price. In Model 2, after considering the random effects of individual levels, for each additional unit of story, common area, and private area, the price increases by NTD53,725, NTD267,303, and NTD166,524, respectively.In Model 3, in whichonly management costs are considered, these have a significant effect on the average price between buildings.In Model 4, in which the variables in individual and group hierarchies are considered, when the management cost is increased by one unit, the average price increases by NTD40,549.In each residential building, for each additional unit of the story, common area, and private area, the price increases by NTD53,932, NTD245,634, and NTD175,402, respectively. The management cost has a positive and direct effect on the unit price, as do individual characteristics.

The extent to which the common area and private area, respectively, in the buildings affect the transaction price varies according to the model used. The ratios decrease from 2.9:1 in Model 1 to 1.6:1 in Model 2 and to 1.4:1 in Model 4; the ratios are gradually approaching. Under different model conditions, common and private areas have different degrees of effect on prices. The effect of the common or shared area is greater than that of the private area. This finding subverts traditional concepts and previous findings and reflects the current state of real estate transactions.

\section{References}

Benefield,D.J. (2009). Neighborhood Amenity Packages, Property Price,and Marketing Time. Property Management,27(5), 348-370.

Cai, Y. H. (2009). Research on Real Estate Price Factors: Take Beitun District, Xitun District, Nantun District, Central District, East District of Taichung City as an example. Master's thesis of Chaoyang University of Science and Technology, Chaoyang University of Science and Technology, Taiching, Taiwan.

Chan, E. H. W., So, H.M., Tang,B.S., \&Wong,W.S. (2008). Private space, shared space and private housing prices in Hong Kong: An exploratory study. Habitat International, 32, 336-348.

Chen, S. M., \& Lin, P. X. (2013). Research on the relationship between service quality, satisfaction and real estate value in residential community management and maintenance. Journal of Architecture, 86, 191-205.

Chen, S. M., Lin P. X., \& Chen, Y. R. (2010). Relationship between apartment building residential community management and maintenance services, management fee and real estate price depreciation rate. 10-13.

Huang, M. Z. (2012). Hsinchu City Residential Building Price Analysis-Application of Hierarchical Linear Model. Master's Thesis of Department of Architecture and Urban Planning Chung Hwa University, Chung Hwa University, Hsinchu, Taiwan.

Jim, C. Y., \& Chen, Y. W. (2009). Value of Scenic Views: Hedonic Assessment of Private Housing in Hong Kong. Landscape and Urban Planning, 91, 226-234.

Liang, R. X. (2015). Comparative Analysis of the Effect of Capitalization Rate on Housing Age. Taiwan Land Research, 18(1), 83-113.

Mok, H. M. K., Chan, P. P. K., \& Cho, Y. S., (1995). A Hedonic Price Model for Private Properties in Hong Kong. Journal of Real Estate Finance and Economics, 10(1), 37-48.

So, T. P. A., \&Leung, Y. T. A. (2004). Survey on Attitudes Towards Buildings in Three Chinese cities: Hong Kong,Shanghai andTaipei. Facilities, 22, 100-108.

Tong, Z. J. (2008).Multi-level analysis of housing characteristic price model. Master's Thesis of Real Estate Management Department of National Pingtung Institute of Commerce and Technology, National Pingtung University of Science and Technology, Pingtung,Taiwan.

Tse, Y. C. R., \&Love, E.D.P. (2000). Measuring Residential Property Values in Hong Kong. Property Management, 18(5), 366-374.

Tse, Y. C. R. (2000). Estimating Neighbourhood Effects in House Prices : Towards a New Hedonic Model Approach. Urban Studies, 39(7), 1165-1180.

Wang, Y. W., Zhang, J. E., and Jiang, Y. H. (2018). What is the Price of Neighborhood Facilities? - Discussion on the Way of Housing Pricing Method. Institute of Lands and Political Science, National Chengchi University,Taipei,Taiwan.

Wen, X. L., \& Lin, Z. Y. (2009).Study on the relationship between the management costs of community-type collective housing in Taipei area and the types of public facilities, Proceedings of the Third Property Management Research Achievement Conference of the Taiwan Property Management Association,Taiwan.

Wen, F. X., \& Qiu, H. Z. (2012). Multilevel Model Methodology-Key Problems and Trial Solutions of Hierarchical Linear Models. Taiwan: Future Career Publishing Corporation.

Zhang, S. X., \&Lin, X. J. (2018). Multilevel Model (HLM) and Repeated Measures: Using SPSS Analysis. Taiwan: Wu-Nan Book Inc. 